\title{
El mito, el rito y la educación: puntos de encuentro, riesgos y esperanzas ${ }^{1}$
}

\section{Myth, Rite and Education: Meeting Points, Risks and Hopes}

\author{
Leonardo OTÁLORA COTRINO \\ Universidad Jorge Tadeo Lozano - Bogota - Colombia
}

Recibido: Junio 2011

Aceptado: Diciembre 2011

\section{Resumen}

Esta investigación se propone encontrar las relaciones entre el mito, el rito y la educación dentro del contexto de crisis propio del mundo contemporáneo.

En este marco, y desde el terreno de una antropología pedagógica, esta indagación se plantea inquietudes sobre dichas relaciones, buscando posibles salidas ante problemáticas siempre emergentes. De cara a esta realidad, se proponen lugares de encuentro entre la teoría y la práctica, la educación y lo político, el acto creativo y las diversas dimensiones de lo educativo. Desde estos puntos nodales se hace un aporte reflexivo a la educación, procurando puntualizar en las dinámicas intrínsecas que se establecen en lo epistemológico, lo político, lo ético, lo estético y lo ecológico.

Palabras clave: Educación, mito, rito, mundo moderno, nuevas religiones, nuevas mitologías, nuevas ritualidades, subjetividad, política, ética.

\begin{abstract}
This research aims at establishing the relations between myth, rite and education within the crisis-context of the contemporary world.

Within this frame, and on the field of a pedagogic anthropology, this research sets forth worries concerning those relations, as well as the search for possible ways out of the identified prob-
\end{abstract}

${ }^{1}$ Filósofo de la Universidad Nacional de Colombia y Magister en Educación de la Pontificia Universidad Javeriana. Es profesor de tiempo completo del programa de Publicidad adscrito a la Facultad de Ciencias Humanas, Arte y Diseño de la Universidad Jorge Tadeo Lozano. Tiene a su cargo la cátedra de Sociología Publicitaria y dirige la línea de investigación Publicidad y Sociedad. 
lems. Facing this, it suggests meeting points between theory and practice, education and politics, creative act and different teaching dimensions. Once this nodal point have been established, a reflective contribution to education is made, seeking to point out the intrinsic dynamics established on epistemological, political, ethical, esthetic and ecological fields.

Keywords: Education, myth, rite, modern world, new religious, new mythology, new rituality, subjectivity, politics, ethics.

Cuando se aborda el estudio del mito dos problemas siguen principalmente presentes.

El primero de ellos consiste en la carencia de unidad entre las distintas visiones y en la heterogeneidad de los enfoques desde los cuales se le mira. La división del trabajo y el correlativo divorcio de los campos del conocimiento propios de la modernidad dieron como resultado no uno sino diversos panópticos de la realidad mítico religiosa.

El segundo problema se centra en la presencia cada vez más significativa de lo que pudieran llamarse nuevas formas de religiosidad que cobran cuerpo en la época moderna (Bourdieu, 1982, Sauret , 2001; Vattimo, 1994; Wulf , 2004; Mattelart, 1976; Barthes, 1980, Eliade, 1991 ${ }^{\mathrm{a}}$, Dorfles, 1973). Dicha presencia, por ello mismo, revela el surgimiento de mitos y ritos acomodados a un contexto social de naturaleza compleja. En el momento actual se observa un desplazamiento del fuero religioso a un orden no teísta, decididamente laico, centrado en los dominios político, económico y del conocimiento; el culto al Estado, el culto al progreso y el culto a la razón se consolidan como nuevas las nuevas formas de religiosidad que marcan diferentes espacios de culto al interior de sociedades decididamente más pragmáticas y menos dependientes de algo externo e incontrolable. Se habla entonces de mitos no cosmológicos sino sociológicos, que definen un nuevo escenario hierático. De este modo se está ante una verdadera paradoja de difícil comprensión ya que, así sean estigmatizadas, en la cultura actual subsisten y perduran formas de mistificación que funcionan con el aval de la sociedad, pero con un profundo sentido fetichizante ${ }^{2}$ (Barthes, 1980, Mattelard, 1976): se encumbra particularmente un mecanismo de asunción de nuevas narrativas y de nuevas ritualidades que se ajustan perfectamente al sistema de mercado y en particular al auge de la industria cultural y, dentro de ella, de la publicidad. Dicho de otro modo, puede sostenerse que en un contexto histórico y cultural que tiende a la homogenización no solo de los comportamientos, los usos y las costumbres, sino de los valores, los sueños

${ }^{2}$ El Mitologías Barthes hace un análisis semiológico de los mitos que rodean los objetos y las prácticas culturales, mostrando elocuentemente las creencias que se forman en torno a ellos, más allá de su valor funcional. En ese sentido le da aliento al análisis del mito sobre realidades asociadas a la sociedad de masas y en particular a la sociedad que consume sus propios valores para proteger su aura de legitimidad. Un detergente o un automóvil, en tanto signos, revelan cada uno a su manera lo que la sociedad asocia a su uso y posesión, a la vez que permiten ahondar en el manto de creencias que le dan cuerpo a una moral diversificada por parte de la pequeña burguesía. 
y los imaginarios, caracterizado más que todo por imperativos económicos y utilitaristas, la desacralización del fuero religioso tradicional lleva a una nueva integración de la vivencia religiosa, por lo que el mito y el rito adquieren una distinta significación y orientación en las dinámicas culturales, perdiendo de este modo fuerza como elementos potenciales subsumidos exclusivamente en las religiones teístas (Otálora, 2007).

En síntesis, respecto al ascenso de las llamadas por Salvador Guiner (1994) religiones civiles, cabe destacar, por un lado, que se ve al mito y al rito pasar del plano de la tradición religiosa a un segundo plano de la escena social, en el cual comienza a primar la practicidad, la eficiencia, la rentabilidad sobre la potencialidad narrativa de mundos posibles como sobre el ejercicio cotidiano de la fabulación, la poetización y la plasticidad creativa propios de la conciencia mítica (Cassirer, 2001); y por otro, se presencia el advenimiento de un cambio de orientación en las formas de devoción, de reconocimiento y de construcción de nuevos espacios de sacralidad; es así como surgen nuevas divinidades - la idea, la producción, el consumo, la invención técnica - y nuevos comportamientos colectivos frente a ellas (Paz 1984, 1990a, 1990b). Sin lugar a dudas, la característica del hombre moderno es la de haber desacralizado el universo. La avalancha modernizadora y el consecuente ascenso de unas antropologías decididamente antropocentristas, una tecnocientífica (empirismo y positivismo) y otra filosófica (racionalismo) (Scheler, 1974), dieron un inevitable y paulatino desencanto de las estructuras de organización de las prácticas sociales. La época moderna revela claramente formas de ritualidad emergentes: actividades políticas, económicas, productivas, empresariales, educativas, intelectuales, al interior de las cuales se movilizan e interactúan formas ocultas de determinación histórica y en donde se identifican inclusive espacios de poder privado (Sauret, 2001, Guiner, 1994).

Si en el mundo moderno funcionan perfectamente ciertos comportamientos a partir de los cuales podría hacerse una lectura precisa y detallada de nuevas mitologías y por ende de nuevas formas de ritualidad entonces, a partir de estos llamados nuevos fenómenos religiosos se hacen reconocibles ciertos ceremoniales y ciertas prácticas cultuales que enmascaran una clara intencionalidad religiosa. En forma dinámica se desarrollan y estructuran prácticas que, pese a una apariencia profana, tienen muchas características que las ligan indiscutiblemente a la esfera de lo sagrado. Re-ritualización y remitificación de realidades, emergentes de sentido, con un nuevo carácter sagrado, en medio de particularidades que se entenderían como puramente laicas. Hoy, en las sociedades civilizadas ya no se ven los mismos ritos de pasaje de los adolescentes tal y como se realizaban y se realizan al interior de comunidades tradicionales ${ }^{3}$, caracterizados por la secuencia de pruebas de iniciación para acceder a la adultez; los ritos de

${ }^{3}$ El uso de la expresión de 'sociedades tradicionales' no pretende ser aquí un eufemismo o una atenuación de la inadecuada expresión 'sociedades primitivas' sino una posición que busca estar allende a la discusión semántica en la que, en procura de cierta objetividad, se quiere hacer alusión a aquellas sociedades que usualmente se relacionan con pueblos indígenas, comunidades tribales, sociedades rudimentarias, salvajes, pre-modernas, etc. 
matrimonio adquieren una significación distinta, gobernados más por las lógicas de la moda y del mercado; de la misma manera, el ingreso a sociedades secretas es reemplazado por las dinámicas de especialización de los oficios, normalmente referidos a los principios de la división del trabajo en los cuadros del capitalismo; la iniciación individual, característica en la conformación de las instancias del saber, la justicia y la salud de la comunidad, ahora la circulan los cuadros de políticos frecuentemente burocratizados o los integrantes de los guetos en donde impera la distinción social, la cual se deriva, o bien de un reconocimiento público conferido por los mass-media, del círculo cerrado de la intelectualidad, o de distintas formas de autoridad, todos ellos con un carácter excluyente. Es necesario por lo tanto hacer un reconocimiento de los nuevos centros de confluencia ritual a través de las actitudes significativas propiamente dichas, las cuales se orientan siempre a nuevos valores y búsquedas sociales distintas (Segalen, 2005).

En el mundo moderno, al igual que en el mundo primitivo, observamos acciones humanas con sentido, sólo que en este último la orientación de dichos actos está dada hacia lo religioso, que por otra parte abarca casi todas las dimensiones de la vida, desde lo cultual hasta lo trivial y cotidiano. El cultivar, el cazar o el ir a la guerra tiene un trasfondo religioso. Toda actividad, por simple que sea, está referida a una totalidad; lo humano y lo divino dialogan continuamente, confluyen mutuamente en los mismos acontecimientos y configuran el paisaje de la vida social, como un cosmos dramático interdependiente (Eliade, 1991b). En ese sentido más que hablar de des-ritualización o de desmitificación más bien se podría hacer referencia a una nueva forma de narración y de ritualidad, que se ajusta a las circunstancias históricas determinantes como el consumo, el turismo, el deporte, la distracción dirigida, el desahogo colectivo, el culto al cuerpo, entre otros. Podría decirse además que estas nuevas formas de religiosidad contienen aspectos negativos para una cultura que pasa por alto su significación y los resultados de su operatividad. En especial llama la atención la forma como los medios de comunicación asumen el papel de difusión de los nuevos credos sociales, orientados al consumo, a ritos de igualación que ponen en peligro la subjetividad y al socius al mismo tiempo (Otálora, 2007).

Lejos de diagnosticar, como lo hizo la ilustración, el desaparecimiento de la religión, se vislumbran formas persistentes de la vivencia de lo sagrado (Sotelo, 1994). Si se parte de una transformación de lo religioso más que de su desaparición, entonces ¿cómo entender el ascenso de las nuevas formas de religiosidad en las sociedades altamente desacralizadas? Según el proceso observado, se podría más bien hablar de un lento pero seguro proceso de transposición de lo sagrado, en el cual lo religioso no desaparece sino que se vacía y cambia de rostro a tono con las circunstancias externas.

\section{Mitos y ritos en el contexto social y educativo}

Para abordar la interrelación que se da entre el mito y el rito en cualquier tipo de sociedad puede metafóricamente interpretarse de antemano dicha relación como la corre- 
lación que normalmente se establece entre teoría y práctica, entre representación y presentación, entre libretos y escenificación (Urbina, 2003); luego se debe asumir de acuerdo a lo dicho más arriba sin ningún temor a errar, por una parte, que ni los mitos ni los ritos desaparecen sino que se transforman en el tiempo de acuerdo a contextos sociales e históricos bien determinados, sin ser por ello, como muchos piensan, marginales, y por otra, que la acción ritual está enmarcada por una vivencia de una especialidad y una temporalidad cualitativamente distintas. Uno vez entendido esto se empezarán a establecer las relaciones con el fenómeno educativo, con el fin de mostrar que los mitos y los ritos funcionan en el espacio educativo como unos de los mejores y más efectivos medios para alcanzar la integración social, de acuerdo a precisas solidaridades orgánicas. (Wulf, 2004). Para tal efecto es importante recordar que la presencia del mito y del rito en las diferentes culturas a lo largo del tiempo, obedece a necesidades de consolidación, de establecimiento y de protección de la transmisión de los conocimientos y de las prácticas que dan sentido y valor a dichas culturas (Eliade 1992). Si se mira de cerca la función de la educación, se encuentra con correspondencias simétricas entre el basamento mítico y el educativo; se descubre que la educación, como institucionalización, parte del terreno mítico, que se revela como una forma moderna y adecuada del papel que otrora cumplió el mito en las sociedades primitivas. La educación en las sociedades modernas no hizo otra cosa que truncar el largo proceso de formación dado al sujeto dentro de la comunidad, al lado de la familia, y lo circunscribió a una esfera externa, altamente especializada y focalizada en el otorgamiento de conocimientos cada vez más orientados, bien fuera a un campo del saber específico, o a unas prácticas, destrezas y manipulación de técnicas necesarias para la vida en sociedad.

Se parte del supuesto de que en el espacio educativo, casi a la manera de un santuario, se desarrollan una gran cantidad de rituales y de micro-rituales, que afianzan todo un cuerpo de hábitos y valores que le confieren al estudiante, desde lo más cotidiano de su experiencia, los principios básicos de inclusión y exclusión, de aprobación y reprobación al funcionamiento social a través de representaciones imaginarias del orden que lo abarca (Dubet, 2006). El aprendizaje moral, el afianzamiento en una sociabilidad, y una puesta a punto en el manejo de técnicas y destrezas, a la manera de una cultura instrumental, hacen parte de lo que se espera del niño como adquisición por su paso por la escuela. "L'enfant y est soumis á un code établi, structuré par de normes (le surmoi social) qui sont des schèmes de perception et d'action et qui, intériorisées peu á peu, forment un habitus primaire pour parler comme Bourdieu ${ }^{4} \gg$ (Rivière, 1995, p. 85). Existen una serie de eventos y de gestos que permiten hacer una lectura del espacio escolar como espacio ritual; el primer rito de pasaje reconocido que se opera en la escuela, y quizás uno de los más importantes en la medida en que posibilitará el resto del proceso, es el del paso de la oralidad a la escritura. Y ya entre otros se podría citar

${ }^{4}$ Traducción libre de Leonardo Otálora: "El niño es sometido a un código establecido, estructurado por unas normas que hacen las veces de esquemas de percepciones y de acción y que interiorizadas poco a poco, forman un hábito primario en términos de Bourdieu" 
el valor que adquiere el encierro dentro del lugar de transformación educativa, estableciéndose un poco la relación planteada por Eliade (1991c) entre espacio sagrado y espacio profano, la disposición de las actividades por el toque de campana, que a su vez marca el comienzo de un tiempo fuerte frente a un tiempo débil o de transición, muy a tono con lo anterior, el valor que adquiere entrar o salir de los salones a la hora de la clase, las formaciones según rangos y niveles de ascensión, la izada de la bandera, pasar al tablero, en fin, todas aquellas actividades que denotan claramente la existencia de unos valores en torno a pasos ceremoniales, a lógicas de reconocimiento, de elevación, de selección, de ideales luchados, logrados o perdidos. ¿Y qué decir de las formas de evaluación, de promoción, de censura, las sesiones solemnes, las fiestas conmemorativas, el cierre festivo de actividades, el significado del uso de los uniformes, etc.? Tal vez es en los ritos de graduación en donde se experimenta de manera más profunda lo que significa un rito de pasaje. La iniciación y la culminación de una nueva fase encierran efectivamente el valor simbólico que sólo se le conferiría a un rito de iniciación para un joven dentro de una comunidad aborigen. Por otra parte, y en cuanto a la experiencia lúdica en la escuela, los juegos son la experiencia en donde se marca en forma muy profunda el ritual al servicio del descubrimiento del mundo, de los roles sociales y de las reglas que gobiernan la vida interindividual.

Por su parte Bourdieu (1982) habla de los modernos ritos de institución social como aquellos ritos que reemplazan a los antiguos ritos de iniciación. Inicia su planteamiento desde la teorización de Van Gennep y Victor Turner (Turner ,1988), interesándose sobre todo por aquellos aspectos del rito de pasaje relacionados con la función social del logro, con el reconocimiento que hace la sociedad de pertenecer o no al grupo de los elegidos a partir de su éxito o fracaso en el ritual; esto gracias a la especificidad del iniciado y a la autoridad manifestada por quienes instauran dicho poder. Existe por tanto una frontera o línea que separa un antes y un después, que funciona para denotar un cambio de estatuto, una nueva situación existencial de quien accede a una nueva condición a través del rito. El rito tiene una fuerte carga simbólica gracias a la cual el sujeto consagrado adquiere un valor dentro de las representaciones del grupo que lo separan de su anterior condición. Dicho sujeto goza de una nuevo estatus que lo diferencia netamente de aquellos que quedaron al margen de su nueva posición social, los cuales quedan neutralizados y lejos de sus posibilidades. Sobre el instituido recaen una serie de responsabilidades a las que debe necesariamente ajustarse en la medida en que es aprobado socialmente. Todos aquellos que no han sido instituidos quedan de este modo por fuera del aval social. Lo que caracteriza realmente al rito de institución es que sólo a través de una autoridad mayor instituyente cobra valor el gesto significativo a los ojos de la comunidad; de este modo debe existir un orden reconocido legitimador, tal como la iglesia, la escuela, el estado, una asociación deportiva, los medios de comunicación, etc. El principio del rito de institución, al separar al iniciado de aquellos que no acceden a su nueva condición alcanzada, es el de constituir una forma socialmente aceptada de segregación; así Instituir significa entonces consagrar un estado de cosas que se reconoce socialmente como legítimo en tanto se apela a un estatus sagrado frente a lo que se pudiera llamar condición profana o de ineptitud. El iniciado alcanza 
una investidura que tiene propiamente un carácter político en el buen sentido de la palabra: legitimación social que alberga en el iniciado un valor simbólico, el cual alcanza más poder que el mismo valor real que describe.

De lo anterior se desprende que la escuela, en la medida en que acorta al máximo los espacios de ritualidad subjetiva, frecuentemente acrecienta un esquematismo ritual impuesto y concentra sus esfuerzos en la transmisión de conocimientos, las más de las veces alejados de un entorno concreto, fáctico, dejando así el desarrollo constreñido a su parte formal. De este modo lo moral, lo expresivo y lo político sufren un reduccionismo a la legalidad externa, a una instancia de codificación impuesta. La vida se explica pero no se asume, la realidad se simplifica en cuadros sinópticos, en mapas conceptuales pero no se edifica como debiera desde la acción participante.

En dicho espacio se corre el riesgo de desligar lo cognitivo de su componente social, de dejar de referenciarse un telos supraindividual, propio de la vida en comunidad, y de reducirse el sujeto educado a un rol de cumplimiento de resultados. Así mismo, se exterioriza en forma mecánica el sujeto del mundo, se hacen extraños los aspectos afectivos de los dictados de la razón, el espíritu deseante se encasilla en los logros o en los resultados cuantificables: notas, premios, reconocimientos o en su defecto, rituales impuestos a su vez por el inframundo de los mass media. Podría decirse, teniendo en cuenta los anteriores presupuestos, que en forma frecuente la des-ritualización de lo esencial y la hiper-ritualización de lo innecesario definen el esquema de funcionamiento de las acciones del sujeto en las instituciones educativas.

\section{Puntos de confluencia entre el mito, el rito y la educación}

A continuación se esbozarán las relaciones tácitas y manifiestas entre el universo mítico-ritual y la realidad sociocultural en la que se enmarca le educación. El tener claridad sobre dicha relación apunta a hacer aportes a nivel teórico que nutren la reflexión en torno a las cuestiones pedagógicas en el contexto de la cultura contemporánea, teniendo como referente principal las contribuciones de la antropología pedagógica. Las relaciones que se destacan a continuación se dan por los diferentes puntos de tensión que se mueven, primero entre el rito y la educación, y segundo entre lo político que entra en diálogo con lo ético, lo ecológico y lo educativo. Si se mira con detenimiento estos puntos de encuentro están inspirados en la estructura de la conciencia mítica como forma de acción, en virtud de la cual se entabla una relación participante entre la teoría y la praxis social, entendidas como logos mítico y ritualidad.

\section{Relaciones entre teoría y práctica en el escenario educativo}

En el terreno de lo educativo la falta de elementos contextuales o de saberes pedagógicos, entendidos estos como las concepciones surgidas de las reflexiones sobre la práctica educativa y sus respectivas orientaciones, sirve frecuentemente para crear 
ciertas confusiones acerca de sus fines últimos, al igual que para gestar un campo propicio en donde fácilmente aparecen múltiples debilidades y contradicciones que redundan, o bien en un empobrecimiento del horizonte de la formación de los seres humanos cuando se espera de ellos meros resultados para una vida práctica y, por ende, desligados de unas necesidades sociales vitales; o bien, en una desvirtuación de las potencialidades vitales humanas, en el momento de prefigurar seres pasivos y obedientes ante unas circunstancias sociopolíticas que demandan en forma apremiante la acción de seres autónomos y proposititos (Tardif, 2004). Se enunciarán inicialmente algunas ideas a manera de diagnóstico que servirán como puntos de inflexión críticos para entender dicha problemática y para dar posibles salidas.

- La separación de la producción del conocimiento de su respectiva transmisión, es decir, el distanciamiento entre la investigación científica erudita y las actividades de formación y de educación, sirve decididamente en las sociedades contemporáneas para agudizar un divorcio entre quienes detentan el conocimiento y quienes tienen que acogerlo y repetirlo gracias a un proceso mecánico de transmisión con fines esencialmente prácticos y a veces utilitaristas. Esta separación acentúa en cierta medida el hecho de que se dé una lógica operativa en la cual existen los que saben por un lado, y por otro, los menesterosos, que deben ser puestos al tanto de dicha sabiduría. El grado de autonomía y de heteronomía entre investigadores, docentes transmisores y estudiantes pasivos está en proporción directa a esta jerarquía que define al mismo tiempo y en forma directa, las posibilidades de acción social.

- La separación de los saberes disciplinares y la extrema especialización puede conllevar por otra parte a un proceso de especialismo que dificulta el diálogo entre los distintos campos de conocimiento y que genera visiones hegemónicas respecto a procesos que podrían afrontarse en forma dialogada e interdisciplinar. Así pues, el problema no es sólo tener un ingeniero altamente calificado, o un genetista prodigioso o un filósofo que deslumbra con su discurso y su poder argumentativo, sino saber finalmente hacia dónde va todo este acervo en términos de las necesidades particulares y universales de la sociedad.

- La tendencia al intelectualismo, propia en todos los niveles de la educación y que empieza en los primeros años de aprendizaje, se da a través una escisión o divorcio entre lo que se piensa o lo que se elabora racionalmente y lo que se siente. Esta separación funciona sobre la premisa de que las emociones alejan al sujeto de la verdad, lo hacen menos objetivo y que su comprensión de la realidad queda contaminada de debilidad o subjetividad. Esta aprehensión hacia el aspecto emocional se refuerza después por una acentuación en la enseñanza de campos del conocimiento que se juzgan útiles, prácticos y rentables. De este modo la enseñanza de las artes y, en menor medida, de las ciencias sociales, se tiene como de segunda línea, ocupando un lugar marginal respecto a la 
enseñanza de campos disciplinares más ligados al área productiva industrial, a la explotación de la naturaleza y a técnicas afines a la economía de mercado.

\section{La des-ritualización de lo esencial y la Hiper-ritualización de lo innecesario: una tendencia en la educación}

Si el rito está ligado al aspecto activo, actuante, al ceremonial, si su trasfondo es de carga afectiva y si abarca prácticamente los universos más importantes del desarrollo individual y colectivo dentro del complejo social, incluyendo lo político, lo religioso, lo lúdico, lo cultural en general, lo educativo -en el caso que interesa a esta investigación-, entonces surgen diversas preguntas que advierten su capital importancia ¿Si el rito es un elemento vital en el desarrollo de los actos más significativos del ser humano, por qué casi no se aborda desde el ángulo de los problemas educativos?

Si como se dijo antes, el mito viene a ser el registro narrativo de aquellas actividades grupales que cobran especial significación para la comunidad y de las cuales depende su normal desarrollo y el rito es el elemento axial de dicha praxis humana, ¿por qué no se le confiere una mayor importancia a la hora de buscar salidas a múltiples problemas que se plantean en el núcleo de lo social, específicamente en el terreno de la pedagogía y de las prácticas educativas?

Si el mito es vital como representación para mantener viva la memoria de los actos, de los gestos y de los valores culturales del grupo, y si los actos mismos en los cuales se centra el componente vital de la memoria, que son la definición real de la concepción del desarrollo de la vida, dependen enteramente de una dimensión ritual, entonces ¿cuáles son las vías más expeditas para permitir que el estudio del mito y del rito abra nuevos perspectivas en la elaboración de estrategias de cambio de frente a una sociedad cada vez más paralizada por la diacronía entre el conocimiento y su práctica? ¿Por qué se la ha dado más importancia en el desarrollo de las sociedades modernas -por lo menos en occidente- al problema teórico, conceptual, abstracto, respecto a las preguntas de la vida, llevando en este proceso a una forma exaltada de intelectualización que aleja cada vez más a los seres humanos de su entorno natural y de sí mismos como seres también naturales? ¿Cómo el logos ha ido cogiendo cuerpo hasta asfixiar la esfera del ritual, desprestigiándola, haciéndola secundaria frente al dominio racional ( $\mathrm{Pa}-$ nikkar, 1999), el cual se ha traducido en una nueva religión, cuando es en la esfera de la acción en donde también se resuelven los conflictos intersubjetivos y las formas políticas de consolidación de lo social?

Estas y muchas otras preguntas se deben hacer a la hora de pensar la educación en el milenio que se inaugura. Por lo pronto no se trata de dar respuestas específicas a dichos interrogantes sino de elaborar a título conceptual posibles salidas a la luz de algunas reflexiones que tratan de establecer un diálogo entre el pensar y el hacer, entre el conocimiento y la práctica, entre el logos mítico y el ritual. Jaques Delors (1996), a partir de establecer que la educación del futuro debe basarse en esquemas que superen 
la preponderancia del saber acumulativo sobre el saber-hacer, plantea cuatro pilares fundamentales para alcanzar tal propósito desde la educación. Aprender a conocer, aprender a hacer, aprender a vivir en comunidad y aprender a ser. En una cultura que le ha dado mucho más importancia al saber en términos de conocimiento $\mathrm{y}$, en menor medida, al saber en términos de hacer, el problema del otro y el del ser han pasado respectivamente a un segundo plano si no es que no han sido casi puestos en la invisibilidad o han dependido de circunstancias que los hacen aleatorios. Para que la educación sea una experiencia total y abarque la complejidad de la vida, no sólo de los individuos sino de la sociedad, debe procurar alcanzar estos cuatro derroteros.

Aprender a conocer es necesario e implica para el ser humano, poder afinar la curiosidad intelectual, el sentido crítico, la autonomía del juicio a la vez que permite descifrar lo real (Delors, 1996); pero si este tipo de aprendizaje no se da en un contexto real, si no está referido a una dimensión de aplicabilidad, entonces es realmente insuficiente. Es claro que un stock de conocimientos sólo es importante si con éste se comprende la realidad, si se explota para transformarla de acuerdo a un actual mundo en evolución, si satisface las necesidades de los seres humanos y del planeta que afloran día a día, si ayuda a solucionar impases y problemas que afectan el normal desarrollo de la historia de la humanidad. El no poder 'hacer descender los pensamientos a las manos', el dejarlos en forma abstracta en una esfera de incontaminación de lo real ha dejado y sigue dejando adversas consecuencias en el orden de lo político, de lo económico, de lo religioso y de lo ecológico.

En el aprendizaje de lo abstracto y de lo concreto debe haber complementariedad, indisolubilidad, diálogo permanente, de lo contrario se está negando el fundamento mismo de la complejidad de la vida. Lo humano no sólo se ha fragmentado por una cada vez más creciente especialización de los conocimientos sino también por una pretensión de purismo intelectual y por un culto a la esfera de lo racional que deja por puertas a la vida práctica. "Aquí se enuncia un problema epistemológico: Es imposible concebir la unidad compleja de lo humano por medio del pensamiento disyuntivo que concibe nuestra humanidad de manera insular por fuera del cosmos que lo rodea, de la materia física, y del espíritu del cual estamos constituidos" (Morin, 2000, p. 37). Se es por relación a un entorno, y pretender encerrar la realidad en una dimensión puramente racional, especulativa, en fórmulas, leyes, principios, morales eidéticas, construcciones abstractas y simplificadoras, en ideales de acción, en ideologías y recetas políticas, es simplemente renunciar al otro lado de la vida que reclama un giro continuo entre lo que se piensa, lo que se sabe y lo que se está en condiciones de hacer.

No sólo se es humano, una parte del desarrollo social es también animal y vegetal, esto es, cósmico en el amplio sentido de la palabra. Como lo dice Morin, no cabe duda en el hecho de que:

"Somos resultado del cosmos, de la naturaleza y de la vida, pero debido a nuestra humanidad misma, a nuestra cultura, a nuestra mente y a nuestra conciencia nos hemos vuelto extraños a este cosmos que nos es secreta- 
mente intimo. Nuestro pensamiento y nuestra conciencia, nos hacen conocer este mundo fisico y nos alejan otro tanto. El hecho mismo de considerar racional y científicamente el universo nos separa también de él. Nos hemos desarrollado más allá del mundo físico y viviente. Es en este más allá que se opera el pleno desplegamiento de la humanidad" (Morin, 2000, p. 40).

No es exagerado decir, partiendo de los presupuestos de Delors (1996) que falta aprender a hacer, pero no con la orientación puramente cientificista y tecnocrática pues a partir de ésta se ha hecho ya demasiado, casi hasta quedarse sin materia prima para las nuevas acciones- sino con un sentido más comprometido con el más allá de lo subjetivo individual; hace falta la difícil tarea de reaprender o aprender a vivir en comunidad y a ser. Si esta tarea no se familiariza en la conciencia de las sociedades contemporáneas, si no se naturaliza ${ }^{5}$, entonces hay que empezar a reconocer que se está cada vez más lejos de un ideal de vida digna y dignificante, el cual se funde en la coherencia necesaria entre los principios políticos de acción y sus resultados.

¿Por qué el pensamiento mítico sirve de referencia para postular la necesidad de síntesis entre el pensamiento y la acción y de estos dos para fines altruistas? Ello es posible por cuanto para dicho pensamiento no existe una distinción o separación clara, primero entre la subjetividad y la objetividad, y segundo entre lo que se piensa y lo que se hace, es decir, entre la teoría y la práctica (Cassirer, 1998). Precisamente a partir de la unidad de la conciencia mítica la realidad no se presenta como una disyunción de sub-realidades, como tampoco como la categorización en niveles de importancia por determinación de jerarquía. La conciencia mítica originaria no busca sacar la interioridad del yo y reflejarla en el mundo exterior, tampoco se interesa por traer la realidad trascendente y adecuarla a su propia subjetividad. Por el contrario lo que establece es una interrelación entre el yo y el mundo, entre el sujeto y la naturaleza, en donde no se pueden reconocer límites o fronteras entre alma y cuerpo, entre sujeto y objeto, entre pensamiento y acción. En la estructuración dialéctica entre el mito y el rito es claro que no existe una división entre lo que se cree y lo que se hace, pues en esencia hacen parte de lo mismo. Para la metafísica y para la psicología racional esta síntesis de pensamiento y acción se tornan extrañas e incomprensibles pues están habituadas a organizar la realidad desde una pretensión analítica. Ni el yo ni el mundo natural son esencias por separado para la fenomenología de la conciencia mitológica, lo cual sería una negación de su forma de ser y de estar en el mundo. Es con el desarrollo de las grandes religiones y de la filosofía inmanentista, con la escisión entre alma y cuerpo del judeocristianismo, que se empieza a manifestar la separación del yo como entidad particular

${ }^{5}$ De la misma manera que en un momento dado, a raíz del culto al llamado progreso, se naturalizó en occidente la explotación de la vida silvestre, la vejación de la mujer, la explotación laboral por parte de unas minorías económica y políticamente más poderosas hacia las mayorías más débiles. 
frente a una naturaleza externa y se comienza a desligar por lo tanto una dimensión interna y subjetiva de otra externa y objetiva.

"Es aqui donde la orientación del mito se caracteriza principalmente por efectuar por un modo enteramente distinto la delimitación entre el interior y el exterior y por trazar las líneas divisorias en una posición distinta a como ocurre en la forma del conocimiento empírico-casual. Aquí, ambos factores de la intuición objetiva y del sentimiento subjetivo de sí mismo y de la vida entran en una relación completamente distinta a la que encontramos en la estructura del conocimiento teorético, y ese cambio de acento modifica todas las medidas fundamentales del ser y del acaecer" (Cassirer, 1998, p. 223).

El ritual, como afirmación de una forma de acción inseparable del pensamiento y del sentimiento, tiene un valor incalculable en la relación existente entre acciónpresentación y pensamiento-representación, entre movilidad y quietud. Acceder a la acción saca por breves instantes al sujeto de su invisibilidad ontológica, lo pone en una condición en la cual la dramaturgia no sólo cinética sino emocional le confiere una importancia existencial para actualizar una forma de pertenencia a la vida, para estaren, para estar orientado-hacia. El protagonismo ritual se define por una compenetración de mundo, de realidad hecha a partir de sí y para sí, por un sentimiento de participación en el cual se instala el yo en el centro de lo real sin negarlo ni excluirlo, y se constituye como lo real por excelencia en forma de totalidad, en medio de una subversión espacio-temporal y de una sincronicidad con un entorno trastocado afirmativamente gracias a ciertos pensamientos-acción o a ejecuciones que rompen la unidimensionalidad del estar vivo aisladamente. Coloración de la vida rutinaria, salida a lo irregular, a la invención de realidades posibles.

¿Qué pasa en el campo educativo cuando el sujeto es pensado y tratado como elemento pasivo, des-ritualizado, inerme? Pues, o bien es un repetidor de esquemas y paradigmas o es un espectador de un mundo que sin decírselo, lo quiere y lo necesita como tal. Es el resultado de un sistema que se auto-valida y se legitima a través y gracias a una educación que se perpetúa en sus propios errores. Se tiene por lo tanto la emergencia de acción en dos niveles distintos. El primero, en la enseñanza, en los maestros, en los educadores, en los pedagogos, en la estructura misma educativa como institucionalidad. El segundo, en el terreno del aprendizaje, en los estudiantes, en los niños (as), en los jóvenes universitarios, en los profesionales que trabajan y en la sociedad en general. En ambos niveles se estructura igualmente la continuación del paradigma de la inmovilidad en lo esencial y la superactividad en lo inesencial. En el primer caso se tiene un sistema educativo más dependiente de las estructuras, de los sistemas, del establishment, que de la vida. En el segundo caso se cuenta en forma casi 
generalizada con una juventud inmóvil, acrítica, atélica ${ }^{6}$ como diría Dorfles (1973), espectadora de una realidad en la cual es llamada a participar solo bajo la condición de la obediencia y del no cuestionamiento. Se somete así al estudiante a seguir un camino en el cual se externalizan los problemas a través de la desinformación y se le adiestra en procesos de pensamiento en cuyo seguimiento el elemento ritual está casi ausente. Modelos de pensamiento acordes más a la pasividad que a la reflexividad.

Respecto a la discusión de si lo que realmente prima en la relación enseñanzaaprendizaje, es la participación de los elementos exógenos o culturales o la determinación de las particularidades internas del sujeto, en relación a la interminable pugna entre las pedagogías del sujeto y las pedagogías de lo hetero-estructuración del sujeto, es importante no desconocer la interrelación y complementación de la cultura y del sujeto inmerso en ella (Meirieu, 1997). Adoptar la posición de cualquiera de estas posturas sería desconocer el papel complementario de la otra. ¿Cómo es posible concebir un sujeto sin los elementos conformadores y estructurantes de la cultura que lo determina, de los contenidos de una herencia que le permitirán afirmarse en conjunto o cooparticipativamente? o ¿Cómo ignorar las capacidades propias del sujeto, sus particularidades, sus rasgos distintivos, sus posibilidades de re-creación de la misma cultura ante el papel modelador de la sociedad que muchas veces termina por paralizarla?

Aquí viene el problema del papel del individuo que se debate entre los marcos de referencia sociales y sus capacidades de autodeterminación, entre la moral social externa y su ética individual, entre la inserción pasiva a través de unos rituales performativos de la educación y la emancipación de unos juegos de creación propios de los rituales simbólicos que el individuo eventualmente alcanza por búsquedas personales, entre lo determinante y muchas veces caduco que ofrece la sociedad y el deseo y capacidad expresiva que emancipa al sujeto de ser un repetidor. Frente a esta dualidad, que no es otra cosa que la ambigüedad, lo no linealidad de lo historia, su complejidad, se debe comprender el carácter dialogante entre el aprendizaje y la enseñanza, se debe aceptar el hecho necesario de que la transmisión sólo se da "cuando un proyecto de enseñanza se encuentra con un proyecto de aprendizaje, cuando se forma un lazo, aunque frágil, entre un sujeto que puede aprender y un sujeto que quiere enseñar" (Meirieu, $1997 \mathrm{pp}$. 44-45).

Ahora bien, respecto a los procesos de pensamiento mencionados en párrafos anteriores, es importante entender que éstos se refirieren a las diferentes formas por medio de las cuales el individuo se representa la realidad y actúa en ella; es decir, cómo se piensa a sí mismo y cómo piensa el mundo en términos también de acción. De ahí que representarse a sí mismo y representarse el mundo no pueden desligarse de un hacerse a sí mismo y un hacer el mundo. Pensar la realidad y construir la realidad son dos partes de un mismo todo vital del hombre como ser social e histórico.

${ }^{6}$ Según Gillo Dorfles en 'Nuevos rios, nuevos mitos' (1973 atelia hace referencia a una carencia de fin, a una ausencia de propósito o de telos. 
Acaso uno de los propósitos más importantes en el campo de la educación es el de "enseñar a pensar", pero cabe la pregunta, ¿no es acaso más importante "permitir pensar"? A veces se encuentra con la paradójica situación de que "enseñar a pensar" muchas veces conduce a la situación de "no permitir pensar"; es por ello que resulta tan delicado este propósito pedagógico (Brauner y Burns, 1969). "Enseñar a pensar" y "permitir pensar" tienen que ser dos momentos de un mismo proceso; proceso en el cual, quien aprende debe dar una buena parte, si no la más importante, en la búsqueda del conocimiento. Sin embargo, cuando "se enseña a pensar" sin "permitir pensar", no se dan las condiciones de posibilidad en la pregunta y no se alimenta un diálogo en el descubrimiento de la realidad, por lo que con toda razón y con cierta frecuencia el individuo (el niño, el alumno, el hijo) "no quiere pensar”. ¿Para qué pensar, si otros lo hacen por él? ¿Para qué preguntarle a la vida si ya todo está resuelto en los libros, en las enciclopedias o en el internet? ¿Para qué tomar una actitud ante el conocimiento, y muchas veces ante la vida, si dentro de un contexto utilitario lo único que se espera del sujeto es que no decida, que no piense, que no actúe fuera del marco de unos resultados y un funcionamiento "normal" de la sociedad?

El paternalismo en la educación, lejos de posibilitar la formación de seres reflexivos y determinantes, lo único que genera es un estado de cosas en donde el hombre, como ser pasivo, espera que otros se hagan las preguntas y las resuelvan por él, es decir, que otros conozcan y a la postre él se informe (Zuleta, 1995).

\section{Competencias ciudadanas: una realidad dialógica entre lo político, lo ético, lo ecológico y lo pedagógico}

Intentar comprender lo político, lo ético y lo educativo en una relación complementaria y a la vez universal genera muchas dificultades, pues estos aspectos de lo social que parecen tan obvios y comprensibles tienden a mirarse en forma aislada. Lo político, tal y como se vive en la actualidad se circunscribe a aspectos muy primarios, se encuentra desligado de lo filosófico, lo ético, lo ecológico, y por lo tanto, de lo político mismo. Podríamos decir que se trata de lo no-político o de lo político inesencial.

¿Cómo tener una comprensión de lo político si se exonera al sujeto social de la necesidad de entender la relación de sí mismo con su propio cuerpo, de la manera de relacionarse con el cuerpo social, de vincularse con un hábitat, que no es solamente la ciudad sino el medio ambiente, conformando lo que entiende como una ecología? ¿De qué manera se puede hablar de lo ético en el contexto social, cuando la mímesis de los ciudadanos se pervierte por el abismo tan grande que se establece entre un deber ser moralizante y un ser que anula esos mismos principios en la vida real, cuando los ciudadanos se percatan de que en el comercio de la vida política una cosa es lo que los actores piensan, otra cosa lo que dicen y otra completamente distinta de lo que hacen? ¿Con qué fundamento se aborda el papel, no sólo político sino ético, de la educación cuando se advierte que ésta, desde sus prácticas ha justificado o alimentado una praxis 
de la injusticia que se renueva constantemente, que ha sido en muchos aspectos cómplice en la conformación de un ciudadano pasivo, conformista y obediente ante un sistema que permanentemente lo niega como sujeto? Así, si lo anterior no genera cuestionamientos a nivel ético, entonces, ¿qué es lo que se entiende por ético?

La tarea que se enfrenta respecto a tales retos es ingente y se da como la necesidad de llenar unos vacíos históricos que se agrandan día a día y que se hacen cada vez más insoslayables.

\section{La educación: el lugar de lo político y de lo ético}

Educar ciudadanos nuevos, en condiciones de hacer una re-significación de lo político es la tarea por excelencia de una formación ciudadana que entiende lo público como una experiencia histórico-cultural (Naranjo y Hurtado, 2003). Esta circunstancia reclama la construcción de ciudadanos conscientes de su rol en un contexto más amplio que afecta todos los rincones de lo social; de ciudadanos en condiciones de llevar a cabo la construcción de espacios de auto-referencia, que se sustenten en lo democrático; de ciudadanos que estén en condiciones de vivir lo político en forma responsable en sus prácticas cotidianas (Delgado, 2003). Re-conceptualizar lo político es poder sacarlo de su estatus de inoperancia ideológica, y ponerlo en el plano del diálogo en el cual la pluralidad de los actores sociales pueda llegar a acuerdos de coexistencia, de respeto y de crecimiento colectivo; pero sobre todo, es ponerlo en el plano de la praxis, es decir, estableciendo una relación coherente entre el saber y el saber hacer en el sentido de una verdadera mitopoyesis ${ }^{7}$. El ejercicio de la ciudadanía no se limita al simple uso del voto sino que abarca múltiples planos de acción, de reconquista del espacio cívico, de orientación de la voluntad hacia fines comunes y a la vez individuales, de prácticas cotidianas que le permitan a los sujetos sentirse parte de un todo, en el cual ellos sean una pieza fundamental y decisiva. El ejercicio de la ciudadanía implica una serie de saberes, pero sobre todo de habilidades, de puestas en escena, o dicho en otros términos, de competencias. La formación ciudadana, que entiende lo público como una experiencia histórico-cultural, busca desde lo pedagógico nuevas formas de ser de los ciudadanos, que partan de sus prácticas sociales habituales, de sujetos que actúen (o ritualicen) y piensen críticamente para ejercer sus derechos y que resuelvan creativamente sus problemas sociales, que tengan un sentido compartido de democracia, pero sobre todo, que sientan su responsabilidad política y estén en condiciones de construir identidades dinámicas (Naranjo y Hurtado, 2003).

${ }^{7}$ Dorfles habla de mitopoyesis cuando hace alusión a la dimensión afirmativa o creativa de los universos mítico y ritual. Normalmente en relación con actos llenos de sentido, pletóricos de conciencia, contrariamente a lo que pudiera adoptarse como actos ciegos o costumbres, respecto a los cuales hay una ausencia de pensamiento crítico y en donde normalmente se actúa en forma automática, obedeciendo a ordenamientos externos. 
Contrariamente a lo que se cree, o a lo que muchas veces se obliga a creer en el contexto latinoamericano, en donde hablar de lo político se confunde fácilmente con ideologías, con posiciones radicales, las más de las veces con izquierdas peligrosas, la escuela debería ser el lugar ideal para preparar para la democracia gracias a una comprensión profunda y consecuente de lo político. Quitándole ese cariz negativo, el cual no ha sido otra cosa que un prejuicio útil de las democracias débiles (Zuleta, 1995), a su vez alimentado por la preocupación bien concertada de mantener al ciudadano común y corriente alejado de terrenos siempre peligrosos para el bienestar de algunos, lo político es en esencia el camino expedito para salir de lo que Kant (1986) llama una minoría de edad, que mantiene algunos sectores de la sociedad en una condición de precariedad existencial que ya se mantiene desde hace más de cinco siglos. La historia de América latina ha sido y es la historia de la ignominia, de la desigualdad y de la injusticia, pero también la historia de la abnegación, de las identidades, de los arraigos y de la resistencia. Hasta tanto no se elabore conscientemente esta realidad en las mentalidades y en la memoria de los pueblos, ella seguirá repitiéndose indefinidamente en una espiral que se alimenta gustosa de la desinformación y de la amnesia (Ospina, 1997).

Pero, ¿de qué manera se hace propicia la escuela como un espacio para iniciar a los niños (as) y jóvenes no sólo en la comprensión sino en la vivencia de lo político? Inicialmente en la forma de establecer las relaciones del sujeto con un entorno que exige permanentemente una experiencia inter-relacional edificante, puesto que es en la escuela en donde el niño(a) o el joven entra por primera vez en contacto con el mundo otro, ese que no es familiar, en cuyo interior se está lejos de la tranquilidad de un universo asegurador, en donde todos en principio son iguales, pero a la vez diferentes, en el cual se establece una interrelación de totalidad entre semejantes heterogéneos. En este orden de ideas, la escuela debería ser en principio el lugar por excelencia de la democracia, pero no lo es en tanto que la democracia no siempre es realmente democrática: el mundo real no coincide con el mundo ideal, más bien tiende a contradecirlo o a negarlo. Esa es la paradoja, no de la naturaleza sino de la cultura que la alimenta (Messina, 1997).

Así, si el mundo exterior se presenta habitualmente para el sujeto social más bien como el espacio de la imposibilidad, de la restricción, de la exclusión por la relación inequitativa entre lo público y lo privado $^{8}$, entonces se está en presencia de lo no democrático en términos de espacio y de realización para lo humano.

La escuela democrática es la posibilidad consensuada para dar paso a la fundación de un espacio democrático, ese que la sociedad en muchas ocasiones les niega a sus ciudadanos. Es el lugar de lo político en su más profunda esencia, el del encuentro, el

${ }^{8}$ Entre lo pobre que es de muchos y lo ostentoso que pertenece (casi que por lógica divina) a pocos, entre un deber que se naturaliza en la desgracia de no ser como los 'buenos' y un derecho que se legitima por la lógica de la sangre y del esfuerzo. 
del ir hacia, el del reconocimiento en el mundo, el de la conquista del propio nombre y del propio ser. En ella se inicia la apropiación del mundo bifurcado en comunidad y ciudad-civilidad (Pannikar, 1999). Por ella se reconoce el otro en su diferencia, en su legalidad y el mundo no como dato o insumo, sino como espacio posible de bienestar y de ampliación de la mirada, como paisaje en donde el trayecto no es para alejarse de los congéneres sino para dialogar con su otredad, para resolver conflictos y no para huir de ellos. La escuela democrática es una construcción en pequeño de ese mundo en el que se quisiera contar una historia para revitalizar la memoria.

La escuela es el terreno fértil de re-territorialización del sí mismo, de los otros, del espacio social y del espacio cívico, que ahora se suma a la reconquista de una naturaleza extrañada y arrinconada; le escuela es el lugar indicado y además necesario del cultivo de paradigmas nuevos, de sujetos nuevos, de destinos distintos. El desconocimiento de esta potencialidad de la escuela, y de la continuidad de una inercia frente a esta potencialidad es más grave que el problema mismo, pues eso significa estar en medio de una negatividad de brazos cruzados que no está en condiciones de transformarse en algo afirmativo sino de multiplicar la crisis en la que se debate. El descubrimiento del otro, la reconquista del otro postula la línea de acción indispensable para la recuperación de lo propio individual y colectivo, de lo otro cósmico y universal (Virilio, 1999). Esta es la forma de entender el yo como algo plural, vertido en un más allá de sí mismo, que limita con los propios intereses y con los exaltados y muchas veces invisibles egoísmos. Parafraseando a Wulf:

"El otro ha de ser descubierto; sin él no es posible hoy una educación intercultural. Y también el desarrollo de la sociedad lo precisa como punto de referencia externo hacia el que puede desarrollarse el lado interno de los jóvenes. El otro representa, pues, el exterior, el entorno social al que se mueve el joven, y frente al que también tiene que cerrarse para encontrarse a si mismo como persona individual" (2004, p. 141).

Sin embargo, un elemento obstaculizador para este proceso es la presión que se ejerce en los jóvenes por la estandarización a través de estereotipos, de la moda, de la industria cultural que los sumerge en un consumo auto-justificador, constituyéndose este fenómeno como la muerte política del otro, del mundo y por supuesto, de sí mismo.

Pese a ello, no cabe duda de que la mejor manera de verse a sí mismo es ver que existe algo distinto, algo que existe a pesar de la diferencia, y que existe en forma legítima, que se ubica en el mundo y que lo dignifica de una manera diferente y válida. Para Wulf (2004) como para Delors (1996) esta es una de las claves más importantes para que la educación ayude a comprender el mundo. La educación intercultural ha de servir de espejo pero a la vez de ventana, para mirarse y mirar lo otro. Para comprender al otro se debe aceptar en primera medida lo heterogéneo que habita en cada uno de los seres pensantes (su dualidad, su ambigüedad), todo aquello que hace de él un universo en muchos aspectos insospechado y maravilloso, que está lejos de ser una realidad 
unitaria, medible, analizable como cuerpo inorgánico y puesto en escalas de reducción conceptual (Wulf, 2004). Lo insondable de la subjetividad también es un reflejo de la complejidad del cosmos. Empezar a reconocer con humildad que una de las más grandes fortalezas del ser humano es su dualidad, y que ir detrás de ese misterio es uno de los viajes más alentadores del proyecto llamado vida, es a la vez darle inicio a un proceso de auto-reconocimiento y de reconocimiento del otro que espera ser comprendido:

"Para que cada uno pueda comprender la complejidad creciente de los fenómenos mundiales y dominar el sentimiento de incertidumbre que suscita, en primer lugar debe adquirir un conjunto de conocimientos y luego aprender a relativizar los hechos y a tener espiritu crítico frente a las corrientes de información. La educación manifiesta aqui más que nunca su carácter insustituible en la formación del juicio. Favorece una verdadera comprensión de los hechos más allá de la visión simplificadora o deformada que a veces dan los medios de comunicación, e idealmente debería ayudar a cada cual a convertirse un poco en ciudadano de este mundo turbulento y cambiante que está naciendo ante nuestros ojos" (Delors, 1996 p. 51).

Este viaje de auto-conocimiento, de conocimiento del mundo y de los otros, es condición de posibilidad para una transformación que renueve el aliento y la esperanza en un mejor mañana, viaje que a su vez está condicionado por una nueva visión de la realidad surgida de una posición verdaderamente ética frente a estos fenómenos.

Dentro de este orden de ideas, Estanislao Zuleta (1995) muestra cómo la educación cae frecuentemente en este circuito de utilidad, en donde lejos de constituirse en un proceso de formación y acceso al pensamiento, está ligada a un sistema de producción de fuerza de trabajo calificada para una demanda existente en el mercado, y como tal, se reduce a un simple procedimiento de transmisión de conocimientos adquiridos previamente sin un correlativo crítico ni reflexivo. Para entender la realidad profunda de la educación hay que empezar por hacerse una serie de preguntas -no siempre tranquilizadoras-: ¿para qué se educa? Y ¿es posible una educación libre y liberadora dentro de un sistema que depende más de pretensiones económicas que humanas?

\section{Referencias bibliográficas}

BARTHES, R. (1980). Mitologías. (10ª ed.). México: Siglo XXI Editores.

BOTERO URIBE, D. (1996). El poder de la filosofia y la filosofía del poder. Bogotá : Imprenta Universidad Nacional de Colombia.

BOURDIEU, P. (1982). «Les rites comme actes d'institution ». En: Actes de la recherche en sciences sociales. Volumen 43. 58-63. junio.

BRAUNER, CH. y BURNS, H. (1969). Problemas de educación y filosofía. Buenos Aires: Paidós. 
CASSIRER, E. (1998). Filosofia de las formas simbólicas. México: Fondo de Cultura Económica.

CASSIRER, E. (2001). Antropología filosófica. Introducción a una filosofia de la cultura. (2a ed.). México: Fondo de Cultura Económica

DELGADO, R. (2003). Interrogantes en torno a la formación de las competencias ciudadanas y la construcción de lo público. Consulta en www.javeriana.edu.co/Facultades/Educación/06/fac-nueva/fac-educacióngeneral/articulo-ricardo.pdf-

DELORS, J. (1996). L'Éducation: un trésor est caché dedans. Paris: Editions Odile Jacob

DÍAZ-SALAZAR, R., GUINER, S., y VELASCO F., (eds.) (1994). Formas modernas de religión. Madrid: Alianza Editorial.

DORFLES, G. (1973). Nuevos ritos, nuevos mitos. Barcelona: Editorial Lumen.

DUBET, F. (2006) La escuela de las oportunidades, ¿qué es una escuela justa? Barcelona: Editorial Gedisa.

ELIADE, M. (1991a). Mito y realidad. Barcelona: Editorial Labor.

ELIADE, M. (1991b). Aspects du mythe. Paris: Éditions Gallimard.

ELIADE, M. (1991c). Le sacré et le profane. Paris: Éditions Gallimard.

ELIADE, M. (1992). Initiation, rites, sociétés secrètes. Paris: Éditions Gallimard.

KANT, M. (1986) Respuesta a la pregunta: ¿Qué es la Ilustración? Revista Argumentos, Nos. 14-17, Bogotá.

MATTELART, A. (1976). Medios de comunicación: mito burgués vs. lucha de clases. Bogotá: Editorial Aquelarre.

MEIRIEU, P. (1997). Aprender sí. ¿Pero cómo? Barcelona: Ediciones Octaedro.

MESSINA, G. (1997). Socialización política de los niños en América Latina: Un ensayo de articulación desde la teoría. En Niñez y democracia (pp. 161-200). Bogotá: Editorial Ariel y UNICEF Oficina Regional para América Latina y El Caribe.

MORIN, E. (2000). Los siete saberes necesarios para la educación del futuro. Bogotá: ICFES.

NARANJO, G. \& HURTADO, D. (2003). Modelos de Formación Ciudadana. Medellín: Grupo Formación Ciudadana Red Viva Antioquia e Instituto de Estudios Políticos Universidad de Antioquia. Documento inédito.

OSPINA, W. (1997). ¿Dónde está la franja amarilla? Bogotá: Editorial Norma.

OTÁLORA, L. (2007). La cultura fáustica, un mito de la sociedad mediática y del consumo. En Miradas. Revista de la Facultad de Comunicación Social de la Universidad Santo Tomás. Vol. 2 No. 2, Jul.- Dic. 2007, Bogotá.

OTÁLORA, L. (2008): El mito, el rito y la educación: puntos de encuentro, riesgos y esperanzas. Tesis de Maestría. Facultad de Educación. Pontificia Universidad Javeriana, Bogotá. Tesis sin publicar.

PANIKKAR, R. (1999). El espiritu de la Política. Barcelona: Ediciones Península. 
PAZ, O. (1984). Las peras del olmo. Bogotá: Seix Barral.

PAZ, O. (1990a). La otra voz. Poesía y fin de siglo. Caracas: Seix Barral.

PAZ, O. (1990b). Hombres en su siglo y otros ensayos. Caracas: Seix Barral.

RIVIERE, C. (1995). Les rites profanes. Presses Universitaires de France, Paris.

SAURET, A. (2001). Permanencia del mito. México: Ediciones Coyoacán.

SEGALEN, M. (2005). Ritos y rituales contemporáneos. Madrid: Alianza Editorial.

SCHELER, M. (1974). La idea del hombre y la historia. Buenos Aires: La Pléyade.

TARDIF, M. (2004) Los docentes ante el saber. En: Tardif, Maurice. Los saberes del docente y su desarrollo profesional. (p.p. 25 - 42 y 43 - 81). Madrid: Nuancea S.A. de Ediciones,

TURNER VICTOR W. (1988). El proceso ritual. Estructura y antiestructura. Madrid: Ed. Taurus.

URBINA RANGEL, F. (2003) El corazón del padre. Mito y rito del juego de pelota entre los Uitotos. En: Racionalidad y discurso mítico. Chaparro, Adolfo y Schumacher Christian Ed. Bogotá: Colección Textos de Ciencias Humanas. Centro Editorial Universidad del Rosario.

VATTIMO G. (1994). La sociedad trasparente. Barcelona: Ediciones Paidos.

VIRILIO, P. (1999). El Cibermundo, la política de lo peor. Madrid: Ediciones Cátedra

WULF C. (2004). Introducción a la antropología de la educación. Barcelona: Idea Books.

ZULETA, E. (1995). Educación y Democracia. Un campo de combate. Bogotá: Fundación Estanislao Zuleta. Tercer Milenio.

Correspondencia con el autor

Leonardo Otálora Cotrino

Facultad de Ciencias Humanas, Arte y Diseño

Universidad Jorge Tadeo Lozano

Bogota - Colombia

e-mail: leonardotalora@gmail.com 